NASA Contractor Report 190786

$1 N 20$

\title{
An RL10A-3-3A Rocket Engine Model Using the Rocket Engine Transient Simulator (ROCETS) Software
}

Michael Binder

Sverdrup Technology, Inc.

Lewis Research Center Group

Brook Park, Ohio

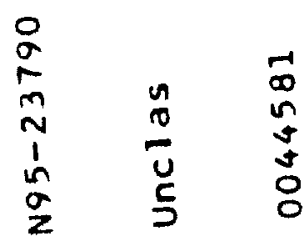

July 1993

Prepared for

Lewis Research Center

Under Contract NAS3-25266

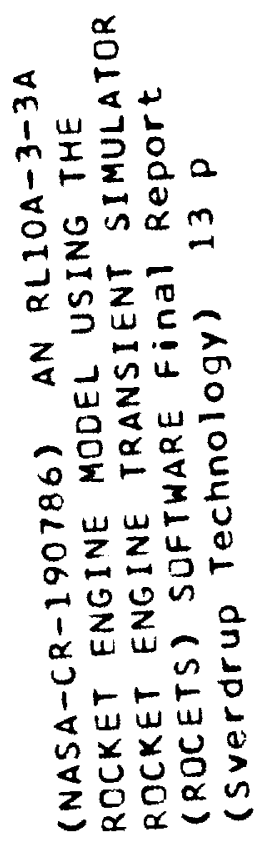

National Aeronautics and

Space Administration 



\title{
AN RL10A-3-3A ROCKET ENGINE MODEL USING THE ROCKET ENGINE TRANSIENT SIMULATOR (ROCETS) SOFTWARE
}

\author{
Michacl Binder \\ Sverdrup Technology, Inc. \\ Lewis Research Center Group \\ 2001 Aerospace Parkway \\ Brook Park, Ohio 44142
}

This work was performed under contract NAS3-25266, NASA Lewis Research Center.

\begin{abstract}
Steady-state and transient computer models of the RL10A-3-3A rocket engine have been created using the ROCket Engine Transient Simulation (ROCETS) code. These models were created for several purposes. The RL10 engine is a critical component of past, present, and future space missions; the model will give NASA an in-house capability to simulate the performance of the engine under various operating conditions and mission profiles. The RL10 simulation activity is also an opportunity to further validate the ROCETS program. The ROCETS code is an important tool for modeling rocket engine systems at NASA Lewis. ROCETS provides a modular and general framework for simulating the steady-state and transient behavior of any desired propulsion system. Although the ROCETS code is being used in a number of different analysis and design projects within NASA, it has not been extensively validated for any system using actual test data. The RL10A-3-3A has a ten year history of test and flight applications; it should provide sufficient data to validate the ROCETS program capability. The ROCETS models of the RL10 system were created using design information provided by Pratt \&Whitney, the engine manufacturer. These models are in the process of being validated using test-stand and flight data. This paper includes a brief description of the models and comparison of preliminary simulation output against flight and test-stand data.
\end{abstract}

\section{Introduction}

The ability to simulate rocket engine system behavior is critical to the successful design and operation of such systems. Rocket engine cycles typically involve the interaction of several non-linear processes including combustion, heat transfer, flow resistance, turbine and pump operation. Relatively subtle variations of such processes can have a dramatic effect on the engine efficiency and stability. Predicting the behavior of rocket engines requires the use of digital computers and a great deal of effort on the part of scientists and programmers. ${ }^{1}$

The RL10A-3-3A rocket engine, manufactured by Pratt \& Whitney, is an important component of commercial and military launches performed by the United States. The RL10 is used to propel the Centaur upper stage vehicles which carry payloads from a high altitude into orbit. The ability to adequately predict the behavior of the RL10 has a significant impact on the success of such missions. The NASA Lewis Research Center bas begun an effort to develop a model of the RL10 for in-house use. This model has been created using design data such as performance maps, line volumes and resistances, and heat transfer correlations supplied by Pratt \& Whitney under contract to NASA (see also Ref.2). Ultimately, the goals of this effort include the development of more detailed RL10 component models using analysis tools which are still under development at NASA.

NASA Lewis has created its version of the RL10A-3-3A computer model using the Rocket Engine Transient Simulator (ROCETS) software. ${ }^{3}$ ROCETS has been selected for this task because it provides a modular, flexible, and powerful modeling capability in a non-proprietary package. The ROCETS program has also been used to model several other rocket engine systems, such as the Space Shuttle Main 
Engine (SSME) and Space Transportation Main Engine (STME). The RL10 modeling activity is an opportunity to evaluate ROCETS capability to simulate the operation of expander cycle engines. Although the RL10 is not highly instrumented, it has a rich database of test-stand and flight operation which can be used to validate ROCETS model output.

ROCETS was designed to perform both steady-state and transient analysis. The first, steady-state version of the RL10 model includes volume, line, and rotor dynamics, but uses a steady-state heat transfer subroutine based on test data. This model was used to predict the performance of the engine at the full power level, and for several different fuelto-oxidizer mixture ratios. These predictions have been compared with Pratt \& Whitney simulations and test-stand data.

The transient version of the RL10 model is derived from the steady-state version, but uses a five node transient heat transfer model suitable for engine-start simulations. The original combustion property tables have also been replaced with tables which cover the lower pressure region of operation (for start-up). The differences between the steadystate and transient model performance predictions at full power are discussed further in subsequent sections of this paper. The transient RL10 model has also been used to simulate the start behavior of the engine. Results from this simulation are compared with flight telemetry data.

In the following sections of this paper, the RL10A-3-3A engine system and its model in ROCETS are discussed in greater detail. A comparison of steady-state model predictions with test-stand data is then presented. Finally, a comparison of start transient behavior with flight data is discussed.

\section{Description of RL10A-3-3A Rocket Engine}

The RL10A-3-3A is a cryogenic hydrogen/oxygen rocket engine manufactured by Pratt \& Whitney for upper stage and orbital transfer applications. The engine system, represented schematically in Figure 1, is based on the expander cycle. In this cycle, heat from the main combustion chamber is transferred to the fuel via a regenerative cooling jacket; the heated fluid is used to drive a turbine. Power from the turbine drives the fuel and oxidizer pumps, connected through a gearbox. The engine develops a rated thrust of $16500 \mathrm{lbf}(73395 \mathrm{~N})$, with a specific impulse of approximately 445 seconds. The fuel turbopump has a design speed of $30000 \mathrm{rpm}$ while the LOX pump design speed is $12000 \mathrm{rpm}$. Combustion chamber pressure is nominally 475 psia. The engine consumes approximately $6 \mathrm{lbm} / \mathrm{sec}$ of hydrogen and 30 $\mathrm{lbm} / \mathrm{sec}$ of oxygen at rated thrust. 2

In its present configuration, the RL10A-3-3A is not intended to be throttled. Chamber pressure is controlled by varying the amount of turbine bypass flow; this is achieved through a pneumatic servo-system which prevents the system from overshooting its desired operating point on start-up. Mixture ratio control is possible in order to optimize propellant utilization during the mission. During start, the engine accelerates to full power using only tank pressure and heat picked up in the cooling jacket; no boost pumps are currently used.

\section{Description of RL10 Model in ROCETS}

The ROCETS code is a general-purpose system analysis code. This code is written in ANSI standard FORTRAN 77 and provides a flexible, modular, and powerful system modeling capability. The ROCETS package includes a library of commonly used component models such as dynamic volumes, flow resistances, pumps, turbines, etc. as well as physical property tables for hydrogen, oxygen, helium, nitrogen, and combustion products. The user may also attach new generic or special purpose component subroutines. The model configuration is defined in a text format, which is then automatically converted into a FORTRAN program. A separate set of instructions directs execution of the model, allowing the same model configuration to be used in a number of different applications, including parametric design, steady-state analysis, transient simulation, and generation of linearized models. ${ }^{3}$ The ROCETS system dramatically reduces the time required to generate and debug model simulation programs.

The ROCETS model of the RL10A-3-3A system is depicted in Figure 2. Each major component is represented by a separate subroutine in this model. Duct volumes and resistances, however, are lumped such that each resistance or volume in the model may actually represent multiple sections of ducts or manifolds. The volumes and resistances are lumped according to recommendations made by Pratt \& Whitney based on their own RL10 engine models.

The first and second stage pump performances are represented by maps (tables) of head coefficient and efficiency versus flow coefficient. ${ }^{4}$ These maps are based on test-stand data. At present, the maps do not contain data for the high and low extremes of flow-coefficient. The LOX pump is represented as fifth-order polynomial curve-fit relationships of bead coefficient and efficiency to flow coefficient. Approximate leakage rates from the pump stages to the gearbox have been included. The fuel turbine performance is represented as a map of efficiency versus velocity ratio. ${ }^{4}$ The turbine pressure drop is modeled in a fashion similar to compressible flow through an orifice.

The steady-state and transient versions of the RL10 model use different heat transfer calculations. The steady-state version uses a map (table) of heat transfer rate versus chamber pressure and mixture ratio based on empirical test 
data. The transient version of the model uses a more complex five-node heat transfer model. In the transient model, the hot-gas side heat transfer coefficients are based on a Bartz correlations while the cool-side cocfficients are determined using a Colburn correlation. The thermal capacity of the metal is taken into account, as well as the volume dynamics of the cooling jacket.

Valves and ducts are both modeled as fluid resistances. Effective areas can be varied to simulate the action of the valves. Actuator dynamics (forces required to actuate valves, pneumatic and hydraulic line pressures, etc.) have not been included in the current model. The flow area of the fuel turbine bypass valve (FTBV) is used to set chamber pressure and thrust. The mixture ratio control valve (MRV) is used to set mixture ratio. For steady-state analysis, it is possible to set these valve areas to a desired value or automatically vary the valve areas until a desired target thrust and mixture ratio are achieved. For start transient operation, the areas of all valves are set according to schedules rather than using closed loop control.

Each dynamic volume module has two state variables: density and internal energy. The combustion chamber pressure, temperature, and mixture ratio, and the fuel pump shaft speed and discharge flow-rate are also system states. These states represent the key dynamic parameters in the system model. Several additional algebraic balances, or 'loops', are also required for this system. The states and additional balances define the Jacobian matrix for the system. This matrix is inverted and used in an iterative Newton-Raphson algorithm to determine model solution. For steady-state analyses, the state time-derivatives are driven to zero. During transient simulations, the integration corrector-term error is driven to zero. ${ }^{3}$

\section{Steady-state model predictions vs. Test data}

In order to verify the steady-state RL10A-3-3A model, system performance was predicted for several different mixture ratios about the rated thrust level of $16500 \mathrm{lbf}$. These steady-state results were compared with the Pratt \& Whitney test-stand data. Tables 1 through 5 show the ROCETS model predictions for ten key performance parameters at five different thrust and mixture ratio settings. The degree of difference between the model and test data is also listed in the tables. Each parameter bas been classified according to the percent difference found between test and model results (in $1 \%$ intervals). The total number of parameters in each percent-error group is then totaled over the five test cases. These percent totals are shown as a histogram in Figure 3.

As indicated by Figure 3, the model predictions are within $4 \%$ of the test data for all measured performance parameters. The figure also indicates that the majority of these predicted values are within $1 \%$ of test results, averaged over the five test cases.

The transient version of the RL10 model was also driven to steady-state for comparison with test data. The principle difference between the steady-state and transient models is in the cooling jacket heat transfer calculation. The steady-state model beat transfer is based on test data while the transient model uses a more complex theoretical calculation as described in the introduction. The results from the transient model do not match the steady-state test data quite as well as the steady-state model does. The RL10 transient model still matches measured test data within $4 \%$, with the exception of turbine inlet temperature, which matches within $7 \%$ in all tests.

\section{Start Transient simulation results vs. Flight Data}

To add transient simulation capabilities to the model used for steady-state analysis above, it was necessary only to replace the steady-state beat transfer model with a dynamic heat transfer model and to extend the hot-gas property tables to include lower chamber pressures; the original version of the model already included volume dynamics, and fluid and rotor inertias. Because the basic RL10A-3-3A engine is not normally throttled, there is no suitable empirical data for mainstage transient operation. In order to validate the ROCETS RL10 model for transient operation, it is necessary, therefore, to compare simulation results with data for start-up and shut-down operations. Thus far, efforts have been focused on modeling the start sequence only. Simulating the start transient operation of an engine is extremely difficult for three reasons: 1) the system pressures are low enough for two-phase flow to exist, 2) the low speed performances of the RL10-3-3A turbines and pumps are not well characterized, and 3) the near zero values of system states leads to numerical instabilities in the simulation itself.

Figures 4, 5,6, and 7 show plots of chamber pressure, venturi inlet pressure, LOX pump speed, and LOX pump discharge pressure respectively. On each plot, simulation results are overlaid with data from Allas/Centaur flight AC69. In each of these plots, the ROCETS prediction parallels the flight data but the acceleration begins too late relative to flight measurements. The simulation results shown here are representative, although it has been observed that the starttime may be earlier or later depending on the choice of initial conditions and other factors as discussed below.

\section{Discussion of Results}

The close correlation of the RL10 steady-state model output with test data, as shown in Figure 3, indicates that ROCETS can accurately predict the performance of the system at mainstage operation. There is good agreement between the various system pressures, temperatures, flows and shaft speeds. It should be noted here that the turbine bypass 
(FTBV) and mixture ratio (MRV) valves are varied, in the engine and in the model, in order to achicve the desired thrust and inlet mixture ratio for the engine. The areas themselves are not actually measured and so the correlation with test data is not known precisely.

It has also been noted that using the transient heat transfer model to predict mainstage steady-state performance is not as accurate as using the heat transfer correlations derived from empirical data. Although the $7 \%$ disagreement in temperatures is not an uncommon degree of error for such models, efforts are currently underway at NASA Lewis to improve the transient beat transfer model.

RL10 modeling efforts at NASA Lewis are presently focused on refining the start transient model. The time at which the system begins accelerating to full-power operation is extremely sensitive to variations in the flow rate through the Interstage Cooldown Valve, and in the fuel pump discharge pressure. The three areas of the RL10 model presently being given closer scrutiny are 1) the turbopump performance maps, 2) the resistance at the pump discharge cutwaters (where the pump impeller and discharge volute meet), and 3) the flow model for the Cooldown Valves. For the first 0.30 seconds of time after the start signal, there is an appreciable flow through the pumps $(0.5$ to $1.5 \mathrm{lbm} / \mathrm{sec})$ while the shaft speed is still relatively low (less than $2000 \mathrm{rpm}$ for the fuel pump). This condition causes the pump to actually dissipate energy from the liquid, creating a pressure drop across the pump. This area of operation has not been extensively tested nor documented for the RL10A-3-3A pumps, and the empirical pump maps do not describe this dissipative effect There may also be an additional fluid resistance due to cavitation in the pump discharge cutwaters. The cavitation losses are included in the model as simple resistances when the pump discharge pressures approach the fluid vapor pressures. The Cooldown Valves, particularly the Interstage valve (see Figure 1), play a major role in the start-transient. The hydrogen will vaporize as it is vented overboard but the location where the vaporization occurs will vary depending on upstream conditions. These effects significantly complicate transient simulation of the start process. If the model predicts too high a pressure drop over the pump, there will be insufficient energy to bootstrap; if too little pressure drop is predicted, the turbine will receive too much power at first and the system will accelerate prematurely. The RL10A-3-3A engine is minimally instrumented, giving limited information with which to understand the true operation of the pumps at start-up. Numerical instabilities during the simulation have also thwarted efforts to determine the correct starting conditions and design parameters via parametric studies. Present RL10 modeling efforts are focused on solving these problems.

In addition to the acceleration delay, there are differences in the shapes of the simulated and flight data curves as the engine approaches full thrust. The RL10A-3-3A uses a pneumatic servo-control system to open the turbine bypass valve (FTBV) at higher chamber pressures. A model of this servo-control has not been available for inclusion in the model. It is believed that actuator dynamics are the cause of the differences in data as the system levels off to full power. The small mismatches in the steady-state levels at the end of the start transient occur because the start simulation is run without closed loop control of thrust level.

\section{Concluding Remarks}

Steady-state and transient computer models of the RL10A-3$3 A$ have been created using the ROCETS software. This effort serves the double purpose of providing NASA with an in-bouse capability to predict the performance of the RL10 engine, and of providing a test case to validate the capabilities of the ROCETS code. The models were created using design information provided to NASA by Pratt \& Whitney. These models have been used to perform steadystate performance predictions and to simulate the system transient behavior during start-up. The predictions from the steady-state model are within $4 \%$ of test data for all measured performance parameters, and most parameters are within 1\% of the test data. The success of the steady-state analyses demonstrates the utility of this model for mainstage performance predictions. The start transient simulation results accurately depict the acceleration of the engine, but the time at which the acceleration process begins differs from that observed in flight. Current efforts are focused on refining the component and system models, particularly in the area of the fuel turbopump, in order to improve the start predictions. With some additional refinements, the transient model will also prove useful for predicting the transient behavior of the engine. The ROCETS code has proven very useful in these modeling efforts, facilitating the creation of the RL10 model with minimal time and effort required to program and debug the simulations. 
1. J.Felder, M.Binder, An Integrated Approach 10 Modeling Space Engines, AIAA Paper 91-3556, September 1991.

2. W.C.Shubert, Design Report for RL1OA-3-3A Rocket Engine, (NASA Contract NAS3-22339, Pratt \& Whitney Report No. FR-15876), January 1982.

3. Pratt \& Whitney Government Engine Business, System Design Specification for the ROCETS System-Final Report, NASA CR-184099, July 1990.

4. Shepperd,D.G., Principles of Turbomachinery, Macmillan Company 1956.

5. Bartz,D.R., A Simplified Equation for Rapid Estimation of Rocket Nozzle Convective Heat Transfer Coefficients, Jet Propulsion Vol.27, pp.29-51, 1957.

6. Holman, J.P., Heat Transfer - Fourth Edition McGraw Hill, 1976. 
Table 1 - Teat Poin 1 - ROCETS vs Test Dala

\begin{tabular}{|c|c|c|c|}
\hline & POCETS & Test Point 1 & ROCETS VS Test \\
\hline $\begin{array}{l}\text { Model Input } \\
\text { THRUST (b) } \\
\text { Inlel OF - Mixture Ratio } \\
\text { FUEL TANK Pressure (stabic psia) } \\
\text { FUEL TANK Temperature (deg R) } \\
\text { LOX TANK Pressure (static psia) } \\
\text { LOX TANK Temperawre (deg A) }\end{array}$ & $\begin{array}{r}16603.00 \\
5.63 \\
27.00 \\
38.60 \\
35.80 \\
174.70\end{array}$ & & \\
\hline $\begin{array}{l}\text { Output } \\
\text { Fuel Pump Disch Pressure (static psia) } \\
\text { Fuel Pump Inlet Volumetric Flow (opm) } \\
\text { Venturi Inlet Pressure (static psia) } \\
\text { Turbine Inlet Temperature (deg P) } \\
\text { Fuel Injector Manifold Pressure (static psia) } \\
\text { LOX Pump Discharge Pressure (static psia) } \\
\text { LOX Pump Shah Speed (rpm) } \\
\text { LOX Pump Inlet Volumetric Flow (gpm) } \\
\text { LOX Injector Plennum Pressure (static psia) } \\
\text { Combustion Pressure (Inj. face static psia) }\end{array}$ & $\begin{array}{r}1033.26 \\
586.87 \\
799.95 \\
425.09 \\
527.96 \\
598.18 \\
12578.00 \\
206.99 \\
525.90 \\
468.72\end{array}$ & $\begin{array}{r}1061.40 \\
580.60 \\
800.45 \\
439.32 \\
534.19 \\
613.80 \\
12697.00 \\
205.82 \\
532.50 \\
472.35\end{array}$ & $\begin{array}{r}-2.65 \% \\
1.08 \% \\
-0.06 \% \\
-3.24 \% \\
-1.17 \% \\
-2.54 \% \\
-0.94 \% \\
0.57 \% \\
-1.24 \% \\
-0.77 \%\end{array}$ \\
\hline
\end{tabular}

Table 2 - Test Point 2 - ROCETS vs Test Data

\begin{tabular}{|c|c|c|c|}
\hline & ROCEIS & Test Point 2 & ROCETS VS Test \\
\hline $\begin{array}{l}\text { Model Inpul } \\
\text { THAUST (Ib) } \\
\text { Inlet OF - Mixture Ratio } \\
\text { FUEL TANK Pressure (static psia) } \\
\text { FUEL TANK Temperabure (deg R) } \\
\text { LOX TANK Pressure (static psia) } \\
\text { LOX TANK Temperature (deg R) }\end{array}$ & $\begin{array}{r}16588.00 \\
5.55 \\
27.00 \\
38.60 \\
35.30 \\
174.70\end{array}$ & & $\cdot$ \\
\hline $\begin{array}{l}\text { Out put } \\
\text { Fuel Pump Disch Pressure (static psia) } \\
\text { Fuel Pump Inlet Volumetric Flow (gpm) } \\
\text { Venturi Inlet Pressure (static psia) } \\
\text { Turbine Inlet Temperature (deg R) } \\
\text { Fuel Injector Manifold Pressure (static psia) } \\
\text { LOX Pump Discharge Pressure (static psia) } \\
\text { LOX Pump Shaft Speed (rpm) } \\
\text { LOX Pump Inlet Volumetric Flow (gpm) } \\
\text { LOX Injector Plennum Pressure (stabic psia) } \\
\text { Combustion Pressure (Inj. lace static psia) }\end{array}$ & $\begin{array}{r}1039.00 \\
593.44 \\
803.95 \\
419.37 \\
528.89 \\
601.86 \\
12617.60 \\
206.08 \\
525.91 \\
469.23\end{array}$ & $\begin{array}{r}1068.90 \\
588.90 \\
808.56 \\
432.92 \\
535.67 \\
619.10 \\
12747.00 \\
205.59 \\
532.67 \\
472.96\end{array}$ & $\begin{array}{r}-2.80 \% \\
0.77 \% \\
-0.57 \% \\
-3.13 \% \\
-1.27 \% \\
-2.78 \% \\
-1.02 \% \\
0.24 \% \\
-1.27 \% \\
-0.79 \%\end{array}$ \\
\hline
\end{tabular}

Table 3 - Tost Point 3 - ROCETS vs Test Data

\begin{tabular}{|c|c|c|c|}
\hline & FOCETS & Test Point 3 & ROCETS vS TUSt \\
\hline $\begin{array}{l}\text { Model Input } \\
\text { THRUST (Ib) } \\
\text { Inlet OFF - Mixture Ratio } \\
\text { FUEL TANK Pressure (static psia) } \\
\text { FUEL TANK Temperature (deg R) } \\
\text { LOX TANK Pressure (stalic psia) } \\
\text { LOX TANK Temperature (deg R) }\end{array}$ & $\begin{array}{r}16458.00 \\
4.99 \\
26.50 \\
38.50 \\
35.80 \\
174.70\end{array}$ & & \\
\hline $\begin{array}{l}\text { Output } \\
\text { Fuel Pump Disch Pressure (static psia) } \\
\text { Fuel Pump Inlet Volumetric Flow (gpm) } \\
\text { Venturi Inlet Pressure (static psia) } \\
\text { Turbine Inlet Temperature (deg R) } \\
\text { Fuel Injector Manilold Pressure (static psia) } \\
\text { LOX Pump Discharge Pressure (static psia) } \\
\text { LOX Pump Shaft Speed (rpm) } \\
\text { LOX Pump Inlet Volumetric Flow (gpm) } \\
\text { LOX Injector Plennum Pressure (static psia) } \\
\text { Combustion Pressure (Inj. face static psia) }\end{array}$ & $\begin{array}{r}1083.44 \\
640.56 \\
836.14 \\
382.29 \\
536.47 \\
634.20 \\
12921.20 \\
200.47 \\
527.44 \\
473.75\end{array}$ & $\begin{array}{r}1112.50 \\
634.90 \\
839.53 \\
390.35 \\
540.20 \\
647.70 \\
13040.10 \\
199.61 \\
531.50 \\
475.48\end{array}$ & $\begin{array}{r}-2.61 \% \\
0.89 \% \\
-0.40 \% \\
-2.07 \% \\
-0.69 \% \\
-2.08 \% \\
-0.91 \% \\
0.43 \% \\
-0.76 \% \\
-0.36 \%\end{array}$ \\
\hline
\end{tabular}


Table 4 - Tost Point 4 - ROCETS ve Test Data

\begin{tabular}{|c|c|c|c|}
\hline & PoceIS & Tost Polnt 1 & ROCETS VS Test \\
\hline $\begin{array}{l}\text { Model Input } \\
\text { THAUST (ib) } \\
\text { Inlet OAF - Mixture Ratio } \\
\text { FUEL TANK Pressure (static psia) } \\
\text { FUEL TANK Temperanure (deg A) } \\
\text { LOX TANK Pressure (static psia) } \\
\text { LOX TANK Temperature (dog A) }\end{array}$ & $\begin{array}{r}16376.00 \\
4.67 \\
26.20 \\
38.50 \\
36.00 \\
174.70\end{array}$ & & · \\
\hline $\begin{array}{l}\text { Output } \\
\text { Fuet Pump Disch Pressure (static psia) } \\
\text { Fuel Pump Inlet Volumetric Flow (opm) } \\
\text { Venturi Inlet Pressure (static psia) } \\
\text { Turbine Inlet Temperature (deg R) } \\
\text { Fuel Injector Manifold Pressure (static psia) } \\
\text { LOX Pump Discharge Pressure (static psia) } \\
\text { LOX Pump Shat Speed (rpm) } \\
\text { LOX Pump Inlet Volumetic Flow (opm) } \\
\text { LOX Injector Plennum Pressure (static psia) } \\
\text { Combustion Pressure (Inj. face static psia) }\end{array}$ & $\begin{array}{r}1111.00 \\
673.44 \\
854.74 \\
359.77 \\
541.16 \\
654.21 \\
13111.60 \\
197.16 \\
528.39 \\
476.42\end{array}$ & $\begin{array}{r}1143.10 \\
667.40 \\
860.85 \\
368.93 \\
543.65 \\
665.90 \\
13236.50 \\
196.34 \\
530.93 \\
476.80 \\
\end{array}$ & $\begin{array}{r}-2.81 \% \\
0.91 \% \\
-0.71 \% \\
-2.48 \% \\
-0.46 \% \\
-1.76 \% \\
-0.94 \% \\
0.42 \% \\
-0.48 \% \\
-0.08 \% \\
\end{array}$ \\
\hline
\end{tabular}

Table 5 - Tost Point 5 - ROCETS vs Tost Data

\begin{tabular}{|c|c|c|c|}
\hline & ROCETS & Test Point 5 & ROCETS VS TEST \\
\hline $\begin{array}{l}\text { Model Input } \\
\text { THRUST (Ib) } \\
\text { Inlet O/F - Mixture Ratio } \\
\text { FUEL TANK Pressure (static psia) } \\
\text { FUEL TANK Temperature (deg R) } \\
\text { LOX TANK Pressure (static psia) } \\
\text { LOX TANK Temperature (deg R) }\end{array}$ & $\begin{array}{r}16555.00 \\
5.42 \\
27.00 \\
38.50 \\
35.50 \\
174.70\end{array}$ & & • \\
\hline $\begin{array}{l}\text { Output } \\
\text { Fuel Pump Disch Pressure (static psia) } \\
\text { Fuel Pump Inlet Volumetric Flow (gpm) } \\
\text { Venturi Inlet Pressure (static psia) } \\
\text { Turbine Inlel Temperature (deg P) } \\
\text { Fuel Injector Manifold Pressure (stabic psia) } \\
\text { LOX Pump Discharge Pressure (static psia) } \\
\text { LOX Pump Shaft Speed (rpm) } \\
\text { LOX Pump Inlet Volumetric Flow (gpm) } \\
\text { LOX Injector Plennum Pressure (static psia) } \\
\text { Combustion Pressure (Inj. face static psia) }\end{array}$ & $\begin{array}{r}1047.21 \\
602.39 \\
809.78 \\
411.17 \\
530.15 \\
607.54 \\
12668.80 \\
204.74 \\
525.84 \\
469.88\end{array}$ & $\begin{array}{r}1076.90 \\
598.40 \\
817.10 \\
420.63 \\
537.03 \\
624.50 \\
12798.00 \\
204.33 \\
532.04 \\
473.03\end{array}$ & $\begin{array}{r}-2.76 \% \\
0.67 \% \\
-0.90 \% \\
-2.25 \% \\
-1.28 \% \\
-2.72 \% \\
-1.01 \% \\
0.20 \% \\
-1.17 \% \\
-0.67 \%\end{array}$ \\
\hline
\end{tabular}




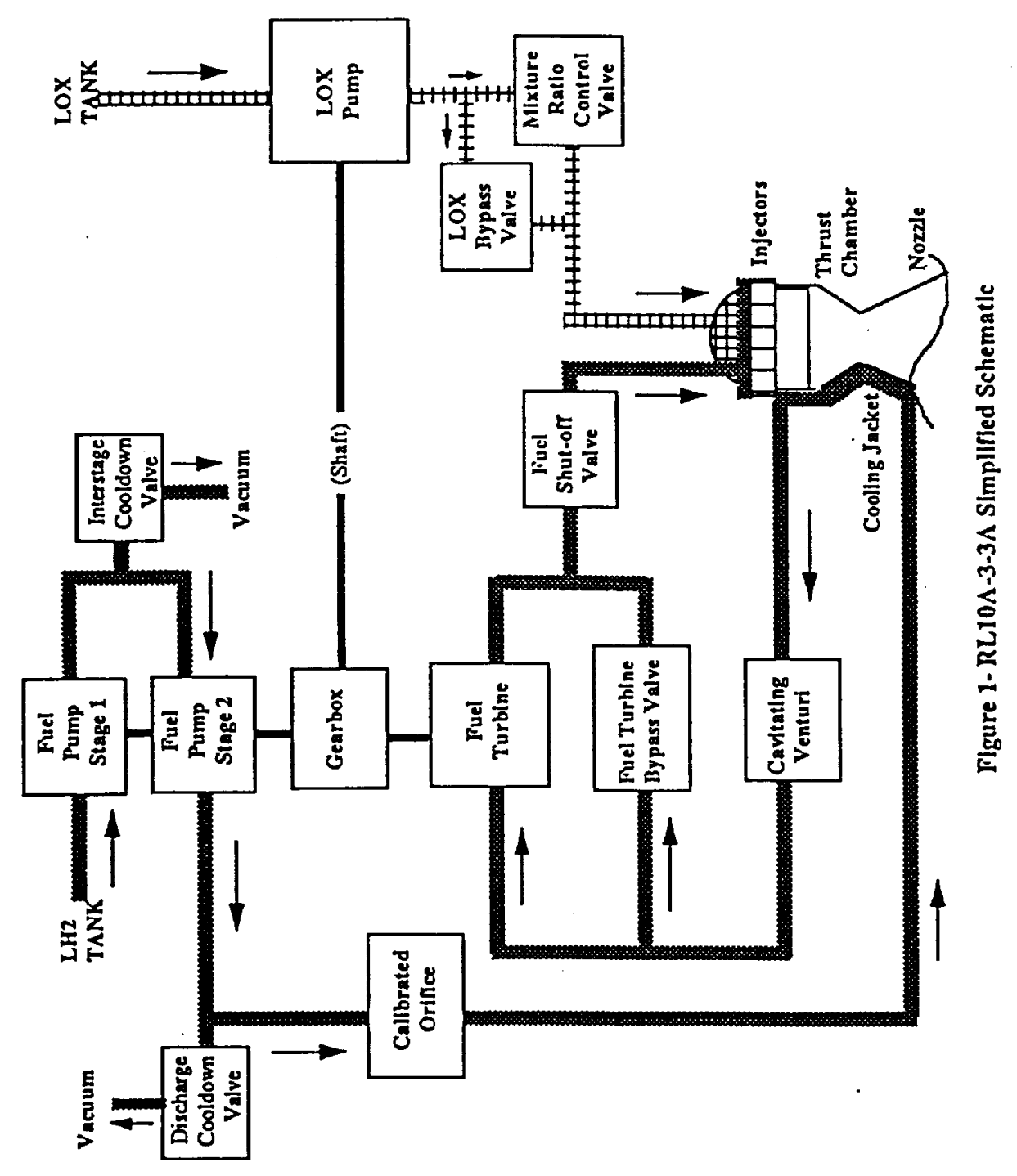




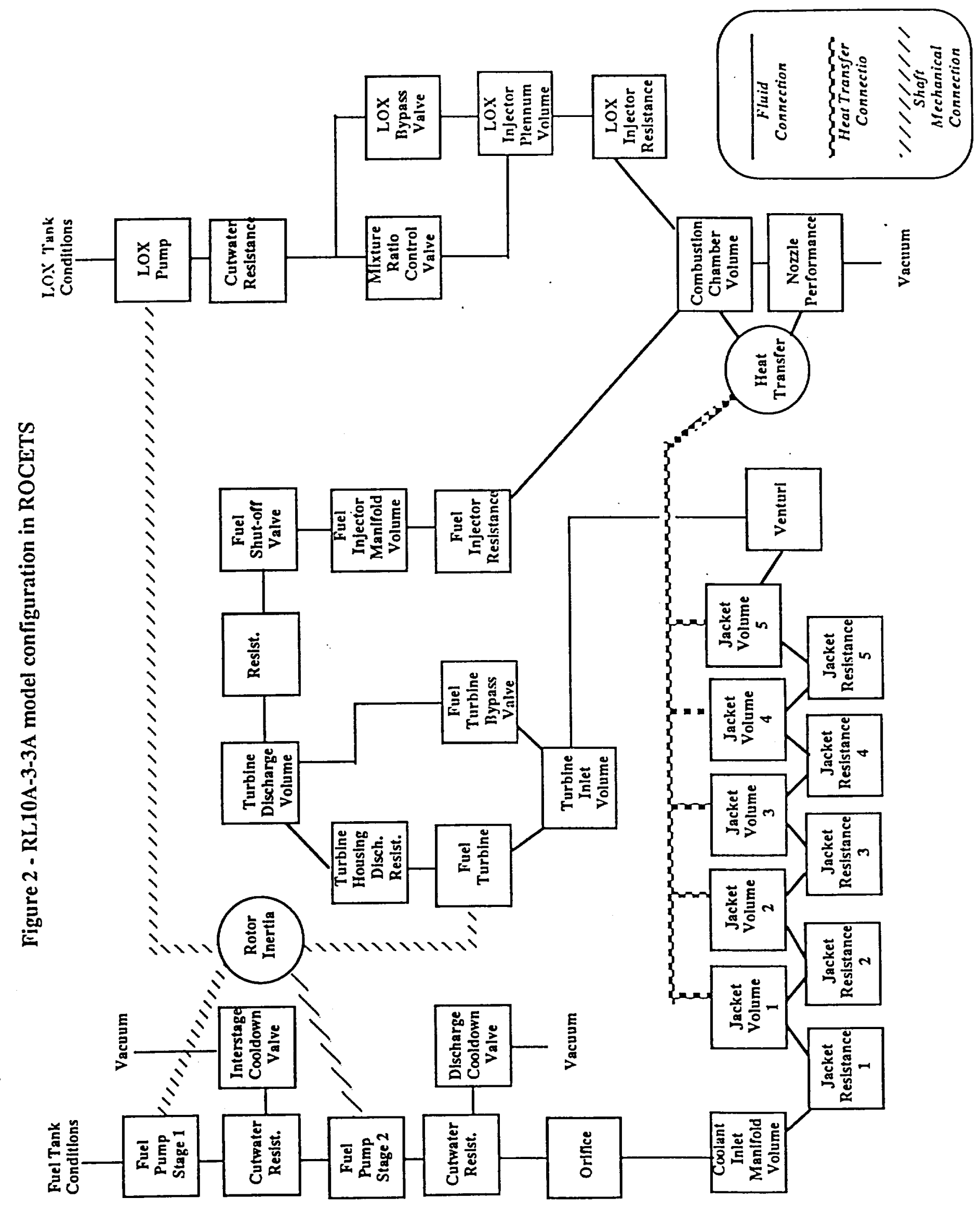




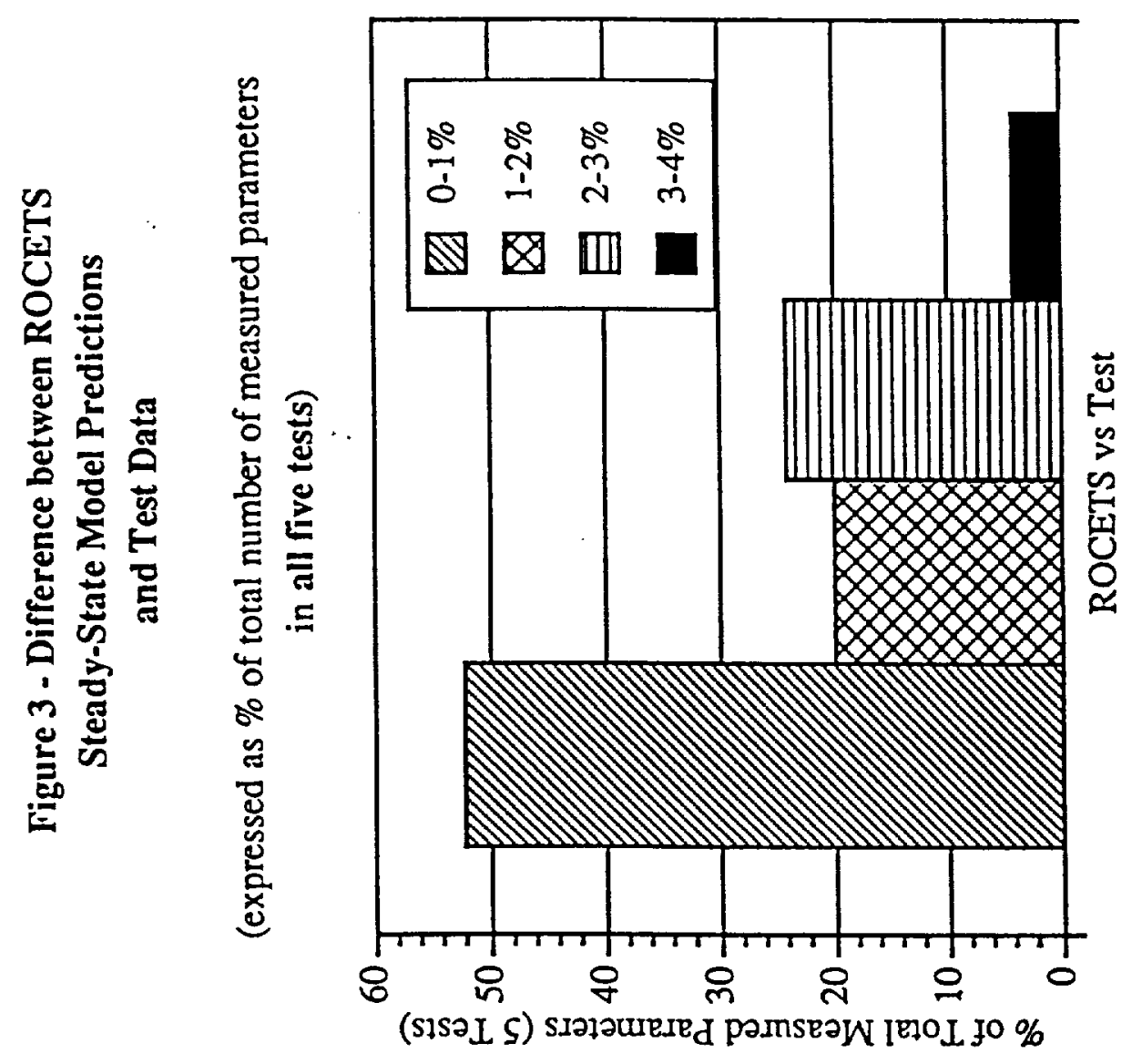



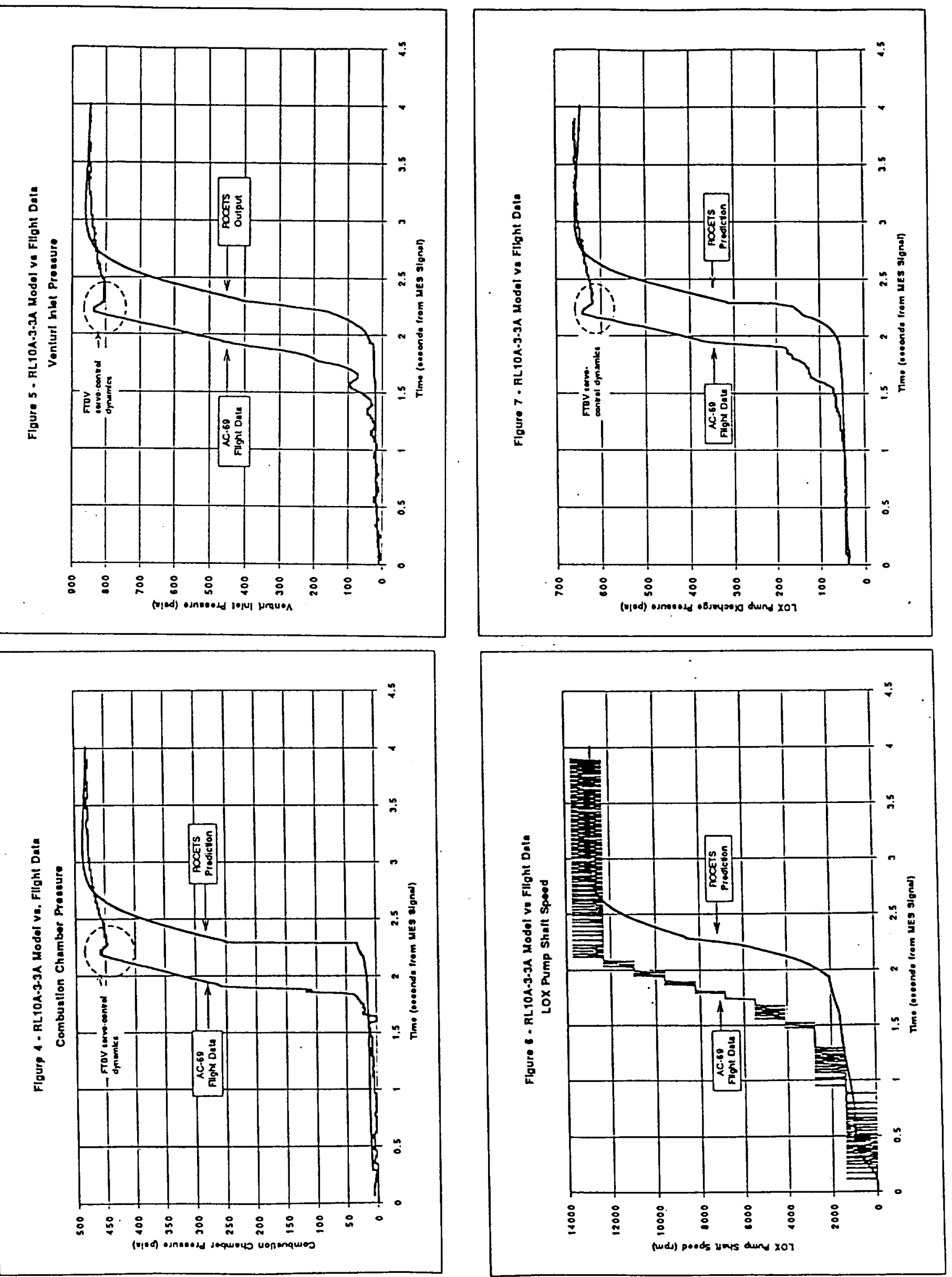
Public reporting burden for this collection of information is estimated to average 1 hour per response, including the time for reviewing instructions, searching existing data sources, gathering and gathering and maintaining the dia neded, an for Dact
1. AGENCY USE ONLY (Leave blank)
2. REPORT DATE
July 1993
3. REPORT TYPE AND DATES COVERED
Final Contractor Report
5. FUNDING NUMBERS

4. TITLE AND SUBTITLE

An RL10A-3-3A Rocket Engine Model Using the Rocket Engine Transient

Simulator (ROCETS) Software

WU-593-12-00

C-NAS3-25266

6. AUTHOR(S)

Michael Binder

7. PERFORMING ORGANIZATION NAME(S) ANO ADDRESS(ES)

Sverdrup Technology, Inc.

Lewis Research Center Group

2001 Aerospace Parkway

Brook Park, Ohio 44142

9. SPONSORING/MONITORING AGENCY NAME(S) AND ADDRESS(ES)

National Aeronautics and Space Administration

Lewis Research Center

8. PERFORMING ORGANIZATION

REPORT NUMBER

E-9585

Cleveland, Ohio 44135-3191

11. SUPPLEMENTARY NOTES

Project Manager, Frank D. Berkopec, Propulsion Technology Division, NASA Lewis Research Center, organization code 5300, (216) 977-7562.

12a. DISTRIBUTION/AVAILABILTTY STATEMENT

12b. DISTRIBUTION CODE

Unclassified - Unlimited

Subject Category 20

This publication is available from the NASA Center for Aerospace Information, (301) 621-0390.

13. ABSTRACT (Maximum 200 words)

Steady-state and transient computer models of the RL10A-3-3A rocket engine have been created using the ROCket Engine Transient Simulation (ROCETS) code. These models were created for several purposes. The RL10 engine is a critical component of past, present, and future space missions; the model will give NASA an in-house capability to simulate the performance of the engine under various operating conditions and mission profiles. The RL10 simulation activity is also an opportunity to further validate the ROCETS program. The ROCETS code is an important tool for modeling rocket engine systems at NASA Lewis. ROCETS provides a modular and general framework for simulating the steady-state and transient behavior of any desired propulsion system. Although the ROCETS code is being used in a number of different analysis and design projects within NASA, it has not been extensively validated for any system using actual test data. The RL10A-3-3A has a ten year history of test and flight applications; it should provide sufficient data to validate the ROCETS program capability. The ROCETS models of the RL10 system were created using design information provided by Pratt \& Whitney, the engine manufacturer. These models are in the process of being validated using teststand and flight data. This paper includes a brief description of the models and comparison of preliminary simulation output against flight and test-stand data.

14. SUBJECT TERMS

Spacecraft propulsion; RL10A-3-3A; Rocket engine; ROCETS

\begin{tabular}{|c|c|}
\hline $\begin{array}{c}\text { 17. SECURTY CLASSIFICATION } \\
\text { OF REPORT }\end{array}$ & $\begin{array}{c}\text { 18. SECURITY CLASSIFICATION } \\
\text { OF THIS PAGE } \\
\text { Unclassified }\end{array}$ \\
Unclassified
\end{tabular}

NSN 7540-01-280-5500
15. NUMBER OF PAGES

13

16. PRICE CODE

$\mathrm{A03}$

19. SECURITY CLASSIFICATION OF ABSTRACT

Unclassified
20. LIMITATION OF ABSTRACT

Standard Form 298 (Rev. 2-89)

Prescribed by ANSI Std. Z39-18 298-102 


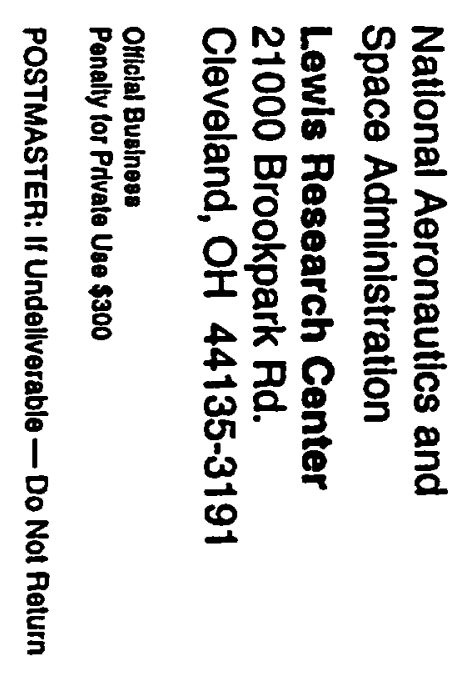


